\title{
Actual preoperative fasting time in Brazilian hospitals: the BIGFAST multicenter study
}

This article was published in the following Dove Press journal:

Therapeutics and Clinical Risk Management

14 February 2014

Number of times this article has been viewed

José E de Aguilar-

Nascimento'

Ana L de Almeida Dias ${ }^{2}$

Diana B Dock-Nascimento ${ }^{3}$

Maria Isabel TD Correia ${ }^{4}$

Antonio CL Campos ${ }^{5}$

Pedro Eder Portari-Filho ${ }^{6}$

Sergio S Oliveira ${ }^{7}$

'Department of Surgery, Julio Muller University Hospital, Cuiaba, Brazil;

${ }^{2}$ Federal University of Mato Grosso,

Cuiaba, Brazil; ${ }^{3}$ Department of

Sciences and Food, Federal University

of Mato Grosso, Cuiaba, Brazil;

${ }^{4}$ Department of Surgery, Federal

University of Minas Gerais, Belo

Horizonte, Brazil; ${ }^{5}$ Department of

Surgery, Federal University of Parana,

Curitiba, Brazil; ${ }^{6}$ Department of

Surgery, Federal University of Rio de

Janeiro State, Rio de Janeiro, Brazil;

${ }^{7}$ Service of Anesthesiology, Julio

Muller University Hospital, Cuiaba,

Brazil

On behalf of the BIGFAST (Brazilian Group for the Study of Preoperative Fasting Time) group

Correspondence: José Eduardo de Aguilar-Nascimento

Rodovia Helder Cândia 2577,

Condomínio Country, Casa I5, 78048-

150, Cuiabá-MT, Brazil

Tel +55 6536237065

$\mathrm{Fax}+556536234020$

Email aguilar@terra.com.br
Background: Prolonged fasting increases organic response to trauma. This multicenter study investigated the gap between the prescribed and the actual preoperative fasting times in Brazilian hospitals and factors associated with this gap.

Methods: Patients (18-90-years-old) who underwent elective operations between August 2011 and September 2012 were included in the study. The actual and prescribed times for fasting were collected and correlated with sex, age, surgical disease (malignancies or benign disease), operation type, American Society of Anesthesiologists score, type of hospital (public or private), and nutritional status.

Results: A total of 3,715 patients (58.1\% females) with a median age of 49 (18-94) years from 16 Brazilian hospitals entered the study. The median (range) preoperative fasting time was $12(2-216)$ hours, and fasting time was longer $(P<0.001)$ in hospitals using a traditional fasting protocol (13 [6-216] hours) than in others that had adopted new guidelines ( 8 [2-48] hours). Almost $80 \%(n=2,962)$ of the patients were operated on after 8 or more hours of fasting and $46.2 \%(n=1,718)$ after more than 12 hours. Prolonged fasting was not associated with physical score, age, sex, type of surgery, or type of hospital. Patients operated on due to a benign disease had an extended duration of preoperative fasting.

Conclusion: Actual preoperative fasting time is significantly longer than prescribed fasting time in Brazilian hospitals. Most of these hospitals still adopt traditional rather than modern fasting guidelines. All patients are at risk of long periods of fasting, especially those in hospitals that follow traditional practices.

Keywords: preoperative fasting, preoperative care, multicenter study, intraoperative complications, guideline adherence, perioperative risk

\section{Introduction}

Preoperative fasting is mandatory for anesthetic induction. However, a concrete body of evidence has demonstrated that prolonged preoperative fasting should be discouraged in healthy patients undergoing elective surgery; ${ }^{1}$ modern guidelines now recommend clear liquids with or without carbohydrates to be taken up to 2 hours before induction of general anesthesia..$^{2-4}$

These recommendations, however, are not followed by a vast number of hospitals; traditional regimens such as nil per oral (NPO) after midnight or even 6-8 hours of total fasting are imposed on most surgical patients. This long period of inconvenient fasting is probably greater due to delays in the surgical theater, maximization of fasting by patients thinking that it is healthy, and changes in daily operation schedules. ${ }^{5}$ The prolonged fasting time for patients waiting to be operated on may compromise their metabolic 
conditioning and may trigger biochemical reactions that initiate gluconeogenesis, lipolysis, and proteolysis. ${ }^{6}$ As a result, insulin resistance is established and, consequently, serum glucose rises. This may contribute to an increased organic response to trauma after the initiation of the surgical procedure.

We previously performed an audit over a period of 6 months in one of the institutions included in the current study. ${ }^{7}$ Before changing the preoperative fasting protocol to 2 hours, we found that the median fasting time was 16 hours and some patients experienced up to 24 hours of fasting. We hypothesized that other hospitals in Brazil would have similar figures. Thus, we conducted this multicenter study aiming to investigate the gap between the prescribed and the actual preoperative fasting time in hospitals from different regions of Brazil. As a secondary objective, we analyzed how the fasting period correlated with some clinical and demographic characteristics of the sample.

\section{Material and methods}

The study was first approved by the Julio Muller Hospital Research Ethics Committee and registered under number 697/CEP-HUJM/09. This study was conducted according to the guidelines of the Declaration of Helsinki; all hospitals involved and their respective Research Ethics Committees approved all procedures involving human subjects/patients. Our team of anesthesiologists and surgeons at Julio Muller University Hospital designed the study protocol and received and organized all information.

A total of 25 hospitals from different regions in Brazil were invited by electronic mail to participate. In addition, either a phone call or personal invitation was sent to a member of the nutritional team at the hospital. Hospitals were invited to participate if they were classified as general institutions regardless of being public or private. In the invitation letter, we stated the purpose of the study and the study design, along with a datasheet containing the variables to be collected. In each hospital, a local coordinator was assigned to be responsible for the collection of the data. To preserve the identity of the various participating hospitals, we encoded everyone using Arabic numerals. However, every local coordinator received the findings of his/her hospital back from the study.

We included consecutive adult patients of both sexes admitted to either general, spinal blockage, or combined (general plus spinal blockage) anesthesia for elective operations scheduled to be performed between August 2011 and September 2012. Patients with missing data on actual preoperative fasting time or those who were operated on under local anesthesia were excluded. The variables of interest were sex, age, surgical disease that motivated the operation (malignant or benign disease), operation type, ASA (American Society of Anesthesiologists) physical status score, nutritional status measured by SGA (subjective global assessment), preoperative fasting time prescribed, and preoperative fasting time executed. Preoperative fasting time executed was defined as the time in hours from the last meal received by the patient ("the patients answered the question: when did you eat or drink your last meal before surgery?") to the time of the initiation of the anesthetic procedure, as recorded on the anesthetic sheet. Hospitals were divided according to their policies as either having a traditional fasting protocol (6-8 hours for solids and clear liquids) or a modern protocol (6-8 hours for solids and up to 2 hours for either clear liquids or carbohydrate beverages). However, some patients in both types of hospitals received the fasting orientation at the discretion of either the surgeon or the anesthesiologist.

\section{Statistical analysis}

The chi-square test was used for comparisons of categorical data. Continuous data were initially analyzed for homogeneity by the Levene test and for normality by the KolmogorovSmirnov test. The Student's $t$-test or Mann-Whitney test was then applied accordingly. The data concerning the actual preoperative fasting time were presented as median, interquartile range, and range rounded to the nearest whole number. All tests were performed using SPSS version 11.0 (IBM Corporation, Armonk, NY, USA). Statistical significance was set at the $5 \%$ probability level $(P<0.05)$.

\section{Results}

Of the 25 invited hospitals, nine either did not reply or did not send the datasheet before the deadline. Data were sent by 16 hospitals as shown in Table 1 . These hospitals were located

Table I Actual preoperative fasting time (hours) according to the type of the surgeries in 3,7I5 patients

\begin{tabular}{llll}
\hline Region or organ & $\mathbf{N}$ & Median (IQR) & Range \\
\hline Gastrointestinal & $\mathrm{I}, 987$ & $12(5)$ & $2-216$ \\
Abdominal wall* & 589 & $13(7)$ & $2-27$ \\
Head and neck & 298 & $9(8)$ & $2-48$ \\
Gynecology & 253 & $1 \mathrm{I}(5)$ & $2-21$ \\
Urology & 177 & $1 \mathrm{I}(9)$ & $2-30$ \\
Soft tissue** & 128 & $9(8)$ & $2-20$ \\
Vascular & 44 & $16(4)$ & $2-19$ \\
Pulmonary & 14 & $17(6)$ & $2-20$ \\
Miscellaneous & 225 & $12(5)$ & $2-28$ \\
\hline
\end{tabular}

Notes: *Herniorrhaphies; **muscle and skin resections. Abbreviation: IQR, inter-quartile range. 
throughout Brazil, in nine of the 27 Brazilian States. The nine non-participating hospitals were public hospitals from the same regions of Brazil (four from the Southeast, three from the South, one from the Northeast, and one from the North) of the 16 that were included. Fourteen $(87.5 \%)$ were public hospitals and two (12.5\%) were private. A total of 3,885 consecutive patients admitted to the hospital were enrolled, and 170 were then excluded due to different reasons. Thus, a total of 3,715 patients were included in the final analysis (Figure 1). The median age was 49 (range 18-94) years and $2,157(58.1 \%)$ were females.

\section{Prescribed preoperative fasting time}

Most of the hospitals $(n=12,75 \%)$ were still adopting a traditional 6-8 hours fasting for solids and liquids or NPO after midnight. Four (25\%) hospitals, however, responded that some patients at the discretion of either the surgeon or the anesthesiologist received a more liberal protocol for fasting (6-8 hours fasting for solids but clear liquids or carbohydrateenriched drinks up to 2-4 hours before anesthesia).

\section{Actual preoperative fasting time}

Only $12.8 \%(n=474)$ of the subjects were operated on after a fasting period less than or equal to 6 hours. The vast majority of the subjects $(n=2,962 ; 79.7 \%)$ were operated on after more than 8 hours of fasting and $46.2 \%(n=1,718)$ after more than 12 hours (Figure 2). The duration of preoperative fasting according to the types of surgeries performed can be found in Table 1. Gastrointestinal surgery was the most prevalent type of operation followed by herniorrhaphies, head and neck surgeries, and gynecologic operations. Treatment of malignancies was the reason for surgery in 1,208 (32.6\%) subjects.

The distribution of the actual fasting times according to the different hospitals is shown in Table 2. The median preoperative fasting time was 12 (range 2-216) hours. This time was greater $(P<0.001)$ in hospitals with $6-8$ hours of preoperative fasting protocol (traditional fasting protocol; median $=13$ hours, range of 6-216 hours) than in those that had already adopted the new guidelines $-6-8$ hours for solid food and up to 2 hours for either clear fluids or carbohydrate

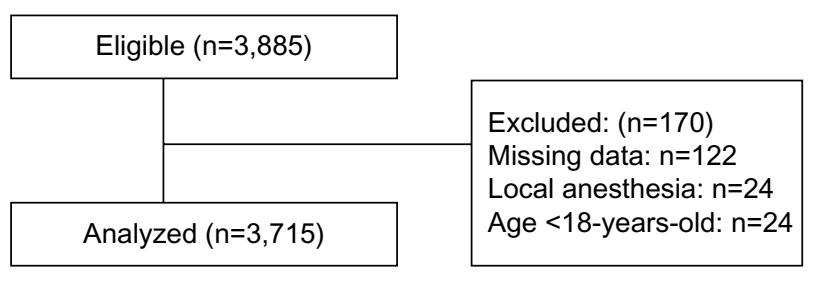

Figure I Flowchart of the study.

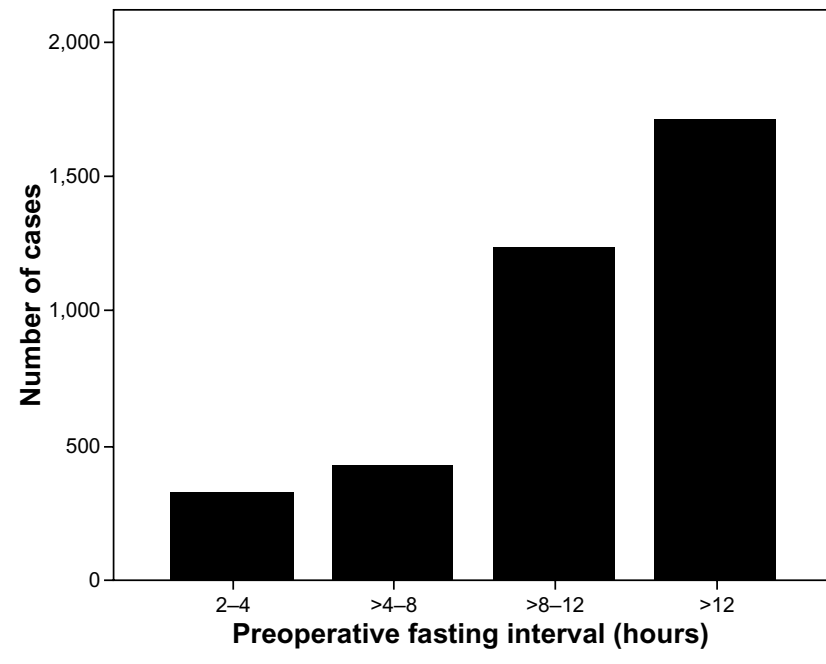

Figure 2 Distribution of cases according to actual preoperative fasting time interval.

drinks (modern fasting protocol; median $=8$ hours, range of 2-48 hours) (Table 3 ). Cases with actual fasting time greater or equal to 24 hours $(\mathrm{n}=52 ; 1.4 \%)$ were individually checked out for reasons for such a prolonged fast. In most cases, the scheduled surgery had been postponed to the next day; the patient received an intravenous crystalloid volume and remained in a fasting condition. One patient fasted for 216 hours. This patient had an obstruction in the esophagus due to a carcinoma. He received only intravenous crystalloid fluids during this period of time.

Table 3 presents the data pertaining to the actual preoperative fasting time findings according to various clinical

Table 2 Ascending median and range of preoperative fasting time (hours) in 15 Brazilian hospitals

\begin{tabular}{|c|c|c|c|c|}
\hline Hospital & Region of Brazil & $\mathbf{N}$ & Median (IQR) & Range \\
\hline I & Southeast & 216 & $4(3)$ & $2-16$ \\
\hline 2 & Central West & 118 & $4(7)$ & $2-17$ \\
\hline 3 & Southeast & 432 & $8(6)$ & $4-24$ \\
\hline 4 & Central West & 469 & $9(9)$ & $2-48$ \\
\hline 5 & Southeast & 146 & II (5) & $2-25$ \\
\hline 6 & Southeast & 657 & II (4) & $4-35$ \\
\hline 7 & Central West & 681 & $13(5)$ & $2-26$ \\
\hline 8 & Southeast & 118 & II (5) & $10-18$ \\
\hline 9 & Southeast & 96 & $13(5)$ & $4-216$ \\
\hline 10 & North & 295 & $14(5)$ & $6-38$ \\
\hline 11 & Southeast & 147 & $15(6)$ & $10-24$ \\
\hline 12 & South & 36 & $15(7)$ & $6-120$ \\
\hline 13 & South & 54 & $16(8)$ & $10-48$ \\
\hline 14 & South & 208 & $16(6)$ & $5-32$ \\
\hline 15 & North East & 10 & $17(6)$ & $14-20$ \\
\hline 16 & Southeast & 32 & $17(8)$ & $8-25$ \\
\hline Total & & 3,715 & $12(6)$ & $2-216$ \\
\hline
\end{tabular}


Table 3 Univariate analysis of various factors influencing preoperative fasting time

\begin{tabular}{|c|c|c|c|c|}
\hline Variable & $\mathbf{N}$ & Median (IQR) & Range & $P$-value \\
\hline \multicolumn{5}{|l|}{ Sex } \\
\hline Male & $\mathrm{I}, 558$ & $12(7)$ & $2-216$ & 0.39 \\
\hline Female & 2,157 & $12(6)$ & $2-96$ & \\
\hline \multicolumn{5}{|l|}{ Nutritional status* } \\
\hline Well-nourished & I,592 & $12(8)$ & $2-120$ & 0.41 \\
\hline Malnourished & 316 & $12(8)$ & $2-216$ & \\
\hline \multicolumn{5}{|l|}{ Disease ${ }^{* *}$} \\
\hline Cancer & $\mathrm{I}, 208$ & II (6) & $2-216$ & $<0.001$ \\
\hline Benign & 2,492 & $12(6)$ & $2-120$ & \\
\hline \multicolumn{5}{|l|}{ ASA } \\
\hline $1-2$ & $\mathrm{I}, 74 \mathrm{I}$ & $12(8)$ & $2-216$ & 0.63 \\
\hline $3-4$ & 156 & II.5 (7) & $3-48$ & \\
\hline \multicolumn{5}{|l|}{ Age } \\
\hline$>60$ years & 1,036 & $12(7)$ & $2-216$ & 0.54 \\
\hline$<60$ years & 2,679 & $12(6)$ & $2-120$ & \\
\hline \multicolumn{5}{|l|}{ Hospital } \\
\hline Public & 2,912 & $12(8)$ & $2-216$ & 0.94 \\
\hline Private & 803 & II.5 (4) & $2-35$ & \\
\hline \multicolumn{5}{|l|}{ Protocol } \\
\hline Traditional & 2,480 & $13(5)$ & $6-216$ & $<0.001$ \\
\hline Liberal & $\mathrm{I}, 235$ & $8(8)$ & $2-48$ & \\
\hline
\end{tabular}

Notes: *Data from I,908 patients; **data from 3,700 patients.

Abbreviations: IQR, inter-quartile range; ASA, American Society of Anesthesiologists.

and demographic variables. Prolonged fasting time was not associated with ASA physical score, age, sex, nutritional status, or type of hospital. Patients who were operated on either in hospitals with a traditional protocol of 6-8 hours fasting or due to a benign disease had an extended duration of preoperative fasting (Table 3).

\section{Discussion}

The overall results showed that in reality and in surgical practice, at least in Brazil, the actual preoperative fasting is extended far beyond the programed period of fasting. This phenomenon leads to a prolonged period of preoperative fasting. In addition, our data clearly showed that although the period of preoperative fasting is usually greater than that prescribed, fasting is shorter in patients receiving the new protocol of 2 hours fasting for carbohydrate-enriched drinks. Similar to our findings, a survey in Germany showed a mean fasting time of 15 hours for solids in 784 participating patients. ${ }^{8}$ As far as we know, these findings are uncommonly reported. Investigators are challenged to conduct similar studies to see if this finding occurs in other countries.

Although nine of the 25 hospitals invited did not reply or return a datasheet, we believe that the 16 hospitals in the study are a representative sample of Brazil. The group of non-participating hospitals are all public hospitals, and are located in the same regions as the 16 that were included.

Prolonged preoperative fasting is quite uncomfortable and harmful for patients. Prolonged fasting increases the sensation of thirst and hunger, as well as nausea, and it negatively impacts the organic response to trauma. A number of randomized trials have shown that the ingestion of beverages containing carbohydrates 2 hours before the induction of anesthesia alleviates these unpleasant symptoms, especially postoperative nausea and vomiting. ${ }^{9,10}$ In addition, insulin resistance after surgery is greater in patients subjected to operations after prolonged fasting. ${ }^{11,12}$ One study has shown that both liver and muscle glycogen are depleted after 12 hours of fasting but increase 2 hours after ingestion of beverages containing carbohydrates. ${ }^{13}$ Recently, a meta-analysis showed that the prescription of multimodal perioperative care that included the abbreviation of preoperative fasting decreased both postoperative infections and length of stay in colorectal operations. ${ }^{14}$ In agreement with these findings, another metaanalysis showed that prolonged fasting increases the length of hospital stay after major operations. ${ }^{15}$

Our data showed that nearly $50 \%$ of the individuals assessed underwent induction of anesthesia after more than 12 hours of fasting. Our findings suggest that a large number of individuals may not be in their best metabolic fitness when presenting for surgery. In this context, physiological studies have clearly shown that after 12 hours of fasting, gluconeogenesis is already initiated and mitochondrial efficacy is impaired, and as a result, adenosine triphosphate production is decreased. ${ }^{13}$

Improvement in communication between nurses, surgeons, and anesthesiologists is the best way to overcome this enormous gap. This is especially important because surgeries may be postponed, delayed, or even cancelled. As a result, this multi-professional work would lead to a reduced preoperative fasting time. ${ }^{16}$

It is interesting to note that age, sex, type of operation, and physical status did not influence the enormous gap between prescribed and actual preoperative fasting times. Prolonged fasting time was seen in all regions of the country; it did not seem to be influenced by either the type of hospital or by the nutritional status of the patients. Possible causes of this inappropriate increase in fasting time include delays in operations, changing schedules of operations, and an extension in the prescribed fasting time by patients believing that this could improve their condition. Although we have not collected data on it, we presume that patients scheduled for the second or third operation of the day may have received 
the same orientation given to patient schedule for the first operation of the day. Unfortunately, we do not have data to support this speculation and thus further data are needed. Such new information might suggest possible strategies for reducing actual fasting times and areas for further study. An interesting finding of this study was that patients with benign disease were at increased risk of having a statistically significant prolonged fasting time. One possible explanation for this finding is that in most cases for benign disease operations in Brazil, patients are admitted to the hospital on the same day of the operation and they therefore start their fast at home. However, the clinical repercussion of a difference of only 1 hour between benign and malignant cases is probably not important. Further studies are needed to explain these findings.

Reality and perception are often far apart in the practice of medicine. ${ }^{17}$ Some studies have clearly shown that what we think we are doing is far from what is really happening, due to a wrong perception of reality. ${ }^{18,19}$ Awareness of a perceptionreality gap in medical care is important when providing continuing medical education and may significantly alter behavior in beneficial ways for patient care. ${ }^{20}$ The perceived period of preoperative fasting among patients undergoing surgery is hardly known. As an example, a Japanese study has shown that a longer fasting period (approximately 12 hours) than the ASA-recommended minimum period, is practiced in anesthesia-teaching hospitals in that country. ${ }^{21}$ Our findings have shown that an enormous gap exists even in hospitals that were presumably following modern guidelines of preoperative fasting. In this study, we hypothesized that there was an enormous gap between the prescribed and actual preoperative fasting times experienced by elective patients. Our findings were in agreement with our hypothesis and showed a large gap in preoperative fasting time. Thus, it seems important at this point to know what it is happening in other hospitals around the world.

\section{Conclusion}

On the basis of our findings, we conclude that actual preoperative fasting time is significantly longer than prescribed fasting time in Brazilian hospitals. Most of the hospitals are still adopting traditional rather than modern preoperative fasting guidelines for their patients. It seems that all patients are at risk, especially those undergoing surgery for benign disease and under traditional preoperative fasting.

\section{Acknowledgments}

We thank BioMed Proofreading LLC, for English correction and copyediting. We also acknowledge the board of directors from the following hospitals: São Luiz Hospital (São Paulo, Brazil), ICESP-Cancer Institute of São Paulo State (São Paulo, Brazil), Bandeirantes Hospital (São Paulo, Brazil), João de Barros Barreto University Hospital (Belem, Brazil), Nossa Senhora da Conceição Hospital (Tubarão, Brazil) Carlos Alberto Studart Gomes Hospital (Fortaleza, Brazil), Luxemburgo Hospital (Belo Horizonte, Brazil), Júlio Muller University Hospital (Cuiabá, Brazil), Hospital de Cancer (Cuiabá, Brazil), Metropolitano Hospital (Várzea Grande, Brazil), Erasto Gaertner Hospital (Curitiba, Brazil), Hospital de Clínicas (Curitiba, Brazil), Gaffrée e Guinle University Hospital (Rio de Janeiro, Brazil), Santa Casa de Misercórdia Hospital (Vitoria, Espírito Santo, Brazil), Hospital do Servidor Público Estadual (IAMSPE-SP) (São Paulo, Brazil), and INCA - National Cancer Institute (Rio de Janeiro, Brazil) for having allowed their inclusion in the study.

Collaborators and members of the Brazilian Group for the Study of Preoperative Fasting Time (BIGFAST): José Eduardo de Aguilar-Nascimento, MD, PhD; Ana Laura Dias, RD; Diana Borges Dock-Nascimento, RD and Romulo Regys Viana Rocha, MD (Júlio Muller University Hospital, Cuiaba, Mato Grosso, Brazil); Pedro Eder Portari Filho, MD, PhD and Bernardo Santos de Souza, MD (Gaffrée e Guinle University Hospital, Rio Janeiro, Brazil); Dan L Waitzberg, MD, PhD, Ariana Lee, RD, Liria Nubia Alvarenga, RD and Thais de Campos Cardenas, RD (ICESP - Cancer Institute of the State of São Paulo, São Paulo, Brazil) Haracelli Leite, RD (Cancer Hospital of Mato Grosso, Cuiaba, Mato Grosso, Brazil) Patricia Ramos, RD, Fabiana Sigrist Bertti, RD and Vivian Palo Pereira Scarpato, RD (Bandeirantes Hospital, São Paulo, Brazil); Diogo Toledo, MD (São Luiz Hospital, São Paulo, Brazil); Márcia Carolina Siqueira Paese, RD and Marcelo Sepulveda Magalhães Faria, MD (Metropolitan Hospital, Várzea Grande, Mato Grosso, Brazil) Gabriela Villaça Chaves, RD and Daiane Spitz de Souza, RD (INCA National Cancer Institute, Rio de Janeiro, Brazil); Maria Isabel Toulson Davisson Correia, $\mathrm{MD}, \mathrm{PhD}$ and Marcelo Portes, MD (Luxemburgo Hospital, Belo Horizonte, Minas Gerais, Brazil); Carlos Onete Coelho Moreira, MD, Carlos Henrique dos Santos, MD and Thais Tapajós Gonçalves, RD (João de Barros Barreto University Hospital, Pará); Álvaro Armando Carvalho de Morais, MD, Rafael Carvalho de Morais, MD, and Gilmária Millere Tavares, MD (Santa Casa de Misercórdia Hospital, Vitoria, Espírito Santo, Brazil); Mayra da Rosa Martins Walczewski, MD, MSc and Tatiane Coan, RD (Nossa Senhora da Conçeição Hospital, Tubarão, Santa Catarina, Brazil); Camila Brandão Polakowski, RD, Vinicius Basso Preti, MD (Erasto Gaertner Hospital, 
Curitiba, Paraná, Brazil); Antonio Carlos L Campos, MD and Talita Cestonaro, RD (Hospital de Clinicas, Curitiba, Parana); Daniel Cordeiro Gurgel, MD, Tiago de Lavor Gama, MD, Abelardo Barbosa Moreira Lima Neto, RD, and Lia Fontenele, RD (Dr Carlos Alberto Studart Gomes Hospital, Fortaleza, Ceará, Brazil); Fernanda Cristina Alves de Lima, RD and Carla Rubino Bacco, RD (Hospital do Servidor Público Estadual [IAMSPE-SP], São Paulo SP, Brazil).

This multicenter study was performed by the Department of Surgery and the Service of Anesthesiology of Federal University of Mato Grosso, Cuiabá, Brazil.

\section{Disclosure}

The authors report no conflicts of interest in this work. This study had no sources of financial support.

\section{References}

1. Maltby JR. Fasting from midnight - the history behind the dogma. Best Pract Res Clin Anaesthesiol. 2006;20(3):363-378.

2. American Society of Anesthesiologists Committee. Practice guidelines for preoperative fasting and the use of pharmacologic agents to reduce the risk of pulmonary aspiration: application to healthy patients undergoing elective procedures: an updated report by the American Society of Anesthesiologists Committee on Standards and Practice Parameters. Anesthesiology. 2011;114(3):495-511.

3. Smith I, Kranke P, Murat I, et al; European Society of Anaesthesiology. Perioperative fasting in adults and children: guidelines from the European Society of Anaesthesiology. Eur J Anaesthesiol. 2011;28(8):556-569.

4. Søreide E, Ljungqvist O. Modern preoperative fasting guidelines: a summary of the present recommendations and remaining questions. Best Pract Res Clin Anaesthesiol. 2006;20(3):483-491.

5. de Aguilar-Nascimento JE, Dock-Nascimento DB. Reducing preoperative fasting time: A trend based on evidence. World J Gastrointest Surg. 2010;2(3):57-60.

6. Ljungqvist $\mathrm{O}$. Modulating postoperative insulin resistance by preoperative carbohydrate loading. Best Pract Res Clin Anaesthesiol. 2009;23(4):401-409.

7. de Aguilar-Nascimento JE, Bicudo-Salomão A, Caporossi C, Silva RM, Cardoso EA, Santos TP. Enhancing surgical recovery in Central-West Brazil: The ACERTO protocol results. e-SPEN, the European e-Journal of Clinical Nutrition and Metabolism. 2008;3(2):e78-e83.

8. Breuer JP, Bosse G, Prochnow L, et al. [Reduced preoperative fasting periods. Current status after a survey of patients and colleagues]. Anaesthesist. 2010;59(7):607-613. German.
9. Hausel J, Nygren J, Thorell A, Lagerkranser M, Ljungqvist O. Randomized clinical trial of the effects of oral preoperative carbohydrates on postoperative nausea and vomiting after laparoscopic cholecystectomy. Br J Surg. 2005;92(4):415-421.

10. Hausel J, Nygren J, Lagerkranser M, et al. A carbohydrate-rich drink reduces preoperative discomfort in elective surgery patients. Anesth Analg. 2001;93(5):1344-1350.

11. Faria MS, de Aguilar-Nascimento JE, Pimenta OS, Alvarenga LC, Dock-Nascimento DB, Slhessarenko N. Preoperative fasting of 2 hours minimizes insulin resistance and organic response to trauma after videocholecystectomy: a randomized, controlled, clinical trial. World J Surg. 2009;33(6):1158-1164.

12. Dock-Nascimento DB, de Aguilar-Nascimento JE, Magalhaes Faria MS, Caporossi C, Slhessarenko N, Waitzberg DL. Evaluation of the effects of a preoperative 2-hour fast with maltodextrine and glutamine on insulin resistance, acute-phase response, nitrogen balance, and serum glutathione after laparoscopic cholecystectomy: a controlled randomized trial. JPEN J Parenter Enteral Nutr. 2012;36(1):43-52.

13. Awad S, Stephenson MC, Placidi E, et al. The effects of fasting and refeeding with a 'metabolic preconditioning' drink on substrate reserves and mononuclear cell mitochondrial function. Clin Nutr. 2010;29(4): $538-544$.

14. Varadhan KK, Neal KR, Dejong CH, Fearon KC, Ljungqvist O, Lobo DN. The enhanced recovery after surgery (ERAS) pathway for patients undergoing major elective open colorectal surgery: a meta-analysis of randomized controlled trials. Clin Nutr. 2010;29(4):434-440.

15. Awad S, Varadhan KK, Ljungqvist O, Lobo DN. A meta-analysis of randomised controlled trials on preoperative oral carbohydrate treatment in elective surgery. Clin Nutr. 2013;32(1):34-44.

16. Pasero C, Belden J. Evidence-based perianesthesia care: accelerated postoperative recovery programs. $J$ Perianesth Nurs. 2006;21(3):168-.

17. Hartman SL, Nelson MS. What we say and what we do: self-reported teaching behavior versus performances in written simulations among medical school faculty. Acad Med. 1992;67(8):522-527.

18. Casey C, Senapati S, White CB, Gruppen LD, Hammoud MM. Medical students self-reported work hours: perception versus reality. Am J Obstet Gynecol. 2005;193(5):1780-1784.

19. Cho YH, Lee SY, Jeong DW, et al. Analysis of questioning technique during classes in medical education. BMC Med Educ. 2012;12:39.

20. Fenton JJ, Egger J, Carney PA, et al. Reality check: perceived versus actual performance of community mammographers. AJR Am J Roentgenol. 2006;187(1):42-46.

21. Shime N, Ono A, Chihara E, Tanaka Y. Current practice of preoperative fasting: a nationwide survey in Japanese anesthesia-teaching hospitals. J Anesth. 2005;19(3):187-192.
Therapeutics and Clinical Risk Management

\section{Publish your work in this journal}

Therapeutics and Clinical Risk Management is an international, peerreviewed journal of clinical therapeutics and risk management, focusing on concise rapid reporting of clinical studies in all therapeutic areas, outcomes, safety, and programs for the effective, safe, and sustained use of medicines. This journal is indexed on PubMed Central, CAS,

\section{Dovepress}

EMBase, Scopus and the Elsevier Bibliographic databases. The manuscript management system is completely online and includes a very quick and fair peer-review system, which is all easy to use. Visit $\mathrm{http}: / /$ www.dovepress.com/testimonials.php to read real quotes from published authors. 